\title{
Overexpression of ATP1B1 predicts an adverse prognosis in cytogenetically normal acute myeloid leukemia
}

\author{
Jin-long Shi ${ }^{1, *}$, Lin Fu ${ }^{2, *}$, Qing Ang ${ }^{1}$, Guo-jing Wang ${ }^{1}$, Jun Zhu ${ }^{1}$ and Wei-dong Wang ${ }^{1}$ \\ ${ }^{1}$ Medical Engineering Support Center, Chinese PLA General Hospital, Beijing, China \\ ${ }^{2}$ Department of Hematology and Lymphoma Research Center, Peking University, Third Hospital, Beijing, China \\ * These authors have contributed equally to this work \\ Correspondence to: Wei-dong Wang, email: wangwd301@126.com
}

Keywords: ATPIBI, expression, prognosis, CN-AML

Received: May 10, $2015 \quad$ Accepted: October 09, 2015

Published: October 25, 2015

This is an open-access article distributed under the terms of the Creative Commons Attribution License, which permits unrestricted use, distribution, and reproduction in any medium, provided the original author and source are credited.

\section{ABSTRACT}

ATP1B1 encodes the $\mathrm{Na}, \mathrm{K}-\mathrm{ATPase} \beta$ subunit, a key regulator of the $\mathrm{Na}^{+}$and $\mathrm{K}^{+}$ electrochemical gradients across the plasma membrane and an essential regulator of cellular activity. We used several microarray datasets to test the prognostic efficacy of ATP1B1 expression in cytogenetically normal acute myeloid leukemia (CN-AML). Within the primary cohort $(n=157)$, high ATP1B1 expression $\left(A T P 1 B 1^{\text {high }}\right)$ was associated with shorter overall survival (OS) and event-free survival (EFS) $(P=$ $0.0068, P=0.0039$, respectively). Similar results were also obtained in the European Leukemia Net (ELN) Intermediate-I genetic category (OS: $P=0.0035$, EFS: $P=$ 0.0007). Multivariable analyses confirmed $A T P 1 B 1^{\text {high }}$ is an independent predictor of shorter OS $(P=0.042)$ and EFS $(P=0.035)$. Analysis of another CN-AML cohort confirmed that ATP1B1 ${ }^{\text {high }}$ is associated with shorter OS $(P=0.0046, n=162)$. In addition, up-regulation of oncogenes/onco-microRNAs such as MYCN, CCND2, CDK6, $K I T$ and miR-155, among others, was associated with ATP1B1 ${ }^{\text {high, }}$ which may be indicative of ATP1B1's leukemogenicity. Our results may improve risk stratification and indicate new therapeutic targets for $\mathrm{CN}-\mathrm{AML}$.

\section{INTRODUCTION}

Cytogenetically normal acute myeloid leukemia (CN-AML) accounts for $40-50 \%$ of all AML [1] and shows significantly heterogeneous outcomes [2]. There are no microscopically detectable chromosome abnormalities in the leukemic blasts of CN-AML patients, but mutations, epigenetic changes and dysregulated expression signatures have been all found and used as biomarkers for prognostic evaluation and risk classification [3]. These include mutations of NPMI [4], CEBPA [5] and FLT3-ITD [6], as well as WT1 [7], DNMT3A [8] and TET2 [9], which are associated with an unfavorable prognosis. Other genes, microRNA and lncRNA [10] found to be associated with prognostic outcomes include $B A A L C, E R G$ [11], WTI [12], DNMT3B [13], TCF4 [14], ITPR2 [15], MAPKBPI [16], miR-155 [17], CXXC5 [18], let-7a-2 and miR-188 [19]. These biomarkers are useful indicators of the degree of malignancy in leukemia, and help focus targeted therapies. However, they do not clarify the treatment intensity necessary to optimize outcome, which is vital for the future lives of CN-AML patients. Consequently, identification of new biomarkers remains an urgent clinical need. In addition, considering that much about leukemogenic mechanisms remains unknown, new biomarkers that shed light on the underlying molecular events may increase our understanding of myeloid leukemogenesis.

Systematic screening for potential biomarkers has been carried out using several bioinformatics approaches with multiple GEO microarray datasets, and gene signatures that showed both aberrant expression and significant prognostic value were identified (See Figure $\mathrm{S} 1$ ). We previously showed that high expression of ITPR2, which encodes a key regulator of transmembrane calcium ion $\left(\mathrm{Ca}^{2+}\right)$ transport, was predictive of an adverse outcome for CN-AML patients [15], which stimulated our interest in regulators of metal ion transport.

$A T P 1 B 1$ encodes $\mathrm{Na}, \mathrm{K}-\mathrm{ATPase} \beta$ subunit, an integral membrane protein essential for establishing and 
maintaining the $\mathrm{Na}^{+}$and $\mathrm{K}^{+}$electrochemical gradients across the plasma membrane. In addition, it was recently reported that targeting of $\mathrm{Na}, \mathrm{K}$-ATPase $\beta$ subunit could induce apoptosis and cell cycle arrest [20], and that impairment of the $\mathrm{Na}, \mathrm{K}$-ATPase $\beta$ subunit increased the incidence of apoptosis among leukemia cells [21, 22]. These results suggest that $A T P 1 B 1$ expression may be a useful indicator of prognosis in CN-AML patients.

\section{RESULTS}

\section{Overexpression of $A T P 1 B 1$ in $\mathrm{CN}-\mathrm{AML}$}

Expression of $A T P 1 B 1$ was significantly higher in bone marrow $(\mathrm{BM})$ from the primary cohort of $157 \mathrm{CN}$ AML patients than in normal BM $(p<0.001$, Figure $1 \mathrm{~A}$, 116 CN-AML vs. 5 normal BM, GEO No: GSE1159), and similar results were obtained using other microarray data (Figure 1B, 9 CN-AML vs. 10 normal BM vs. 10 normal peripheral blood (PB); the $9 \mathrm{CN}-\mathrm{AML}$ consisted of 2 BM and 7 PB samples, GEO No: GSE9476). After dividing the $157 \mathrm{CN}-\mathrm{AML}$ patients into subgroups based the mutation status of FLT3, NPM1 or CEBPA (GEO No: GSE6891) (Figure 1C), ATP1B1 showed significantly higher expression in samples with FLT3-ITD $(n=66)$ than without FLT3-ITD $(n=91)(p<0.001)$. By contrast, there was no significant difference in ATP1B1 expression between $N P M 1$-mutated $(n=82)$ and wild-type samples $(n=75)(p=0.644$, Figure 1C), or between single CEBPAmutated $(n=5)$, double CEBPA-mutated $(n=16)$ and wild-type samples $(n=133)(p=0.376, p=0.305$ and $p=0.492$, respectively, Figure 1C). Finally, significantly higher ATP1B1 expression was detected in the European Leukemia Net (ELN) intermediate-I category than in the ELN-favorable category ( $p=0.003$, Figure 1C).

\section{Pretreatment clinical and molecular characteristics associated with $A T P 1 B 1^{\text {high }}$}

Among the primary cohort, $A T P 1 B 1^{\text {high }}$ expressers included more patients with FAB M1 and M2 $(p=0.02, p$

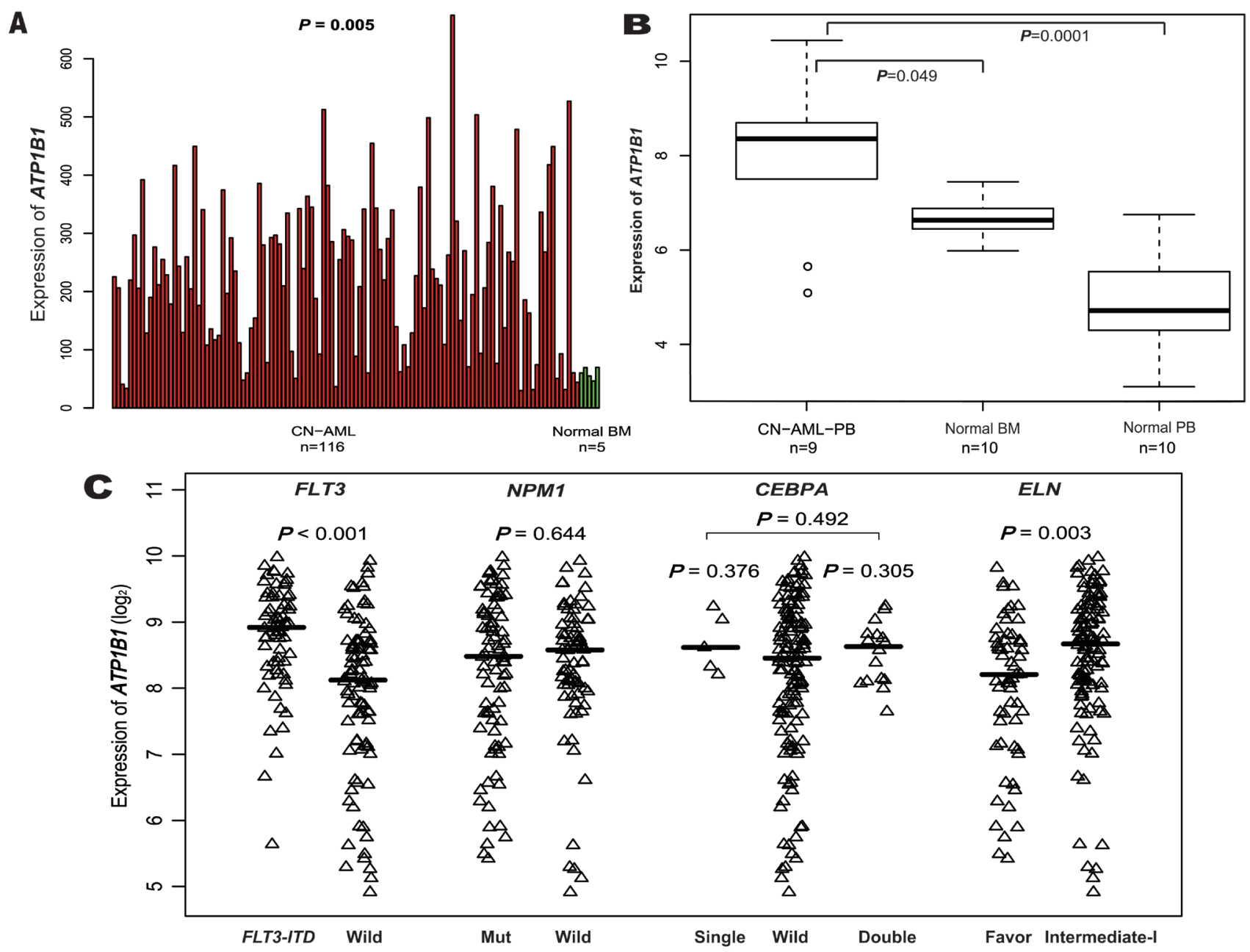

Figure 1: Differential expression of $\boldsymbol{A T P 1 B 1 . ~ ( A ) . ~ C N - A M L ~ a n d ~ n o r m a l ~ B M . ~ ( B ) . ~ C N - A M L ~ a n d ~ n o r m a l ~ B M ~ a n d ~ n o r m a l ~ P B . ~ ( C ) . ~}$ FLT3-ITD, NPM1, mutant and wild-type CEBPA, ELN Favorable and Intermediate-I. 
Table 1: Clinical characteristics of the $157 \mathrm{CN}$-AML patients in the primary cohort segregated based on the $A T P 1 B 1$ expression levels

\begin{tabular}{|c|c|c|c|}
\hline Variable & $A T P 1 B 1^{\text {high }}, n=78$ & $A T P 1 B 1^{\text {low }}, n=79$ & $P$ \\
\hline Median age. y (range) & $49.5(16-77)$ & $50(18-77)$ & 0.38 \\
\hline Female sex, no.(\%) & $35(44.9)$ & $38(48.1)$ & 0.75 \\
\hline \multicolumn{4}{|l|}{ FAB subtype, no. } \\
\hline M0 & 2 & 1 & 0.62 \\
\hline M1 & 29 & 16 & 0.02 \\
\hline M2 & 24 & 8 & 0.0015 \\
\hline M3 & 1 & 0 & 0.5 \\
\hline M4 & 9 & 15 & 0.19 \\
\hline M5 & 10 & 29 & 0.0008 \\
\hline M6 & 0 & 1 & 1 \\
\hline Other & 3 & 9 & 0.13 \\
\hline FLT3-ITD, presented, no. & 45 & 21 & $<0.0001$ \\
\hline NPM1, mutated, no. & 39 & 43 & 0.63 \\
\hline$C E B P A$, single mutated, no. & 3 & 2 & 0.68 \\
\hline$C E B P A$, double mutated, no. & 9 & 7 & 0.5 \\
\hline FLT3-TKD, presented, no. & 7 & 13 & 0.23 \\
\hline$N-R A S$, mutated, no. & 4 & 9 & 0.25 \\
\hline$K-R A S$, mutated, no. & 0 & 1 & 1 \\
\hline IDH1, mutated, no. & 10 & 9 & 0.8 \\
\hline IDH2, mutated, no. & 8 & 5 & 0.4 \\
\hline \multicolumn{4}{|l|}{ ELN genetic group, no. } \\
\hline Favorable & 24 & 35 & 0.1 \\
\hline Intermediate-I & 69 & 53 & 0.002 \\
\hline High $E R G$, no. & 52 & 26 & $<0.0001$ \\
\hline High $B A A L C$, no. & 53 & 25 & $<0.0001$ \\
\hline High $L E F 1$, no. & 39 & 39 & 1 \\
\hline High $M N 1$, no. & 51 & 27 & 0.0001 \\
\hline High $W T 1$, no. & 52 & 26 & $<0.0001$ \\
\hline High $D N M T 3 B$, no. & 56 & 22 & $<0.0001$ \\
\hline High $T C F 4$, no. & 50 & 28 & 0.0004 \\
\hline High ITPR2, no. & 59 & 19 & $<0.0001$ \\
\hline High $M I R 155 H G$, no. & 48 & 30 & 0.004 \\
\hline High $M A P K B P 1$, no. & 54 & 24 & $<0.0001$ \\
\hline High $D N M T 3 A$, no. & 50 & 28 & 0.0004 \\
\hline High $S P A R C$, no. & 48 & 30 & 0.004 \\
\hline High $C X X C 5$, no. & 56 & 22 & $<0.0001$ \\
\hline
\end{tabular}

Abbreviations: FAB, French-American-British classification; ITD, internal tandem duplication; TKD, tyrosine kinase domain; ELN, European Leukemia Net.

High ERG, BAALC, LEF1, MN1, WT1, DNMT3B, TCF4, ITPR2, DNMT3A, MIR155HG, MAPKBP1, SPARC and CXXC5 expression were defined as an expression level above the median of all samples, respectively.

$=0.0015$, respectively) and fewer with FAB M4 and M5 $(P=0.19, p=0.0008$, respectively). In the ELN genetic categories, more $A T P 1 B 1^{\text {high }}$ expressers were within intermediate-I $(P=0.002)$, while fewer were within favorable genetic categories. More $A T P 1 B 1^{\text {high }}$ expressers also carried FLT3-ITD, and several known unfavorably prognostic biomarkers were up-regulated in CN-AML (ERG, BAALC, MN1, WT1, DNMT3B, TCF4, ITPR2, DNMT3A, SPARC, CXXC5, MAPKBP1 and MIR155HG) (See Table 1 and Figure 2). 
Table 2: Multivariable analysis with OS and EFS in the primary cohort of $157 \mathrm{CN}$-AML patients

\begin{tabular}{|l|l|l|l|l|}
\hline \multirow{2}{*}{ Variable } & $\mathrm{OS}, \mathrm{n}=157$ & $\mathrm{EFS}, \mathrm{n}=157$ \\
\cline { 2 - 5 } & $\mathrm{HR}(95 \% \mathrm{CI})$ & $\mathrm{P}$ & $\mathrm{HR}(95 \% \mathrm{CI})$ & $\mathrm{P}$ \\
\hline ATP1B1 expression, high $V S$ low & $1.56(1.02-2.40)$ & 0.042 & $1.55(1.03-2.33)$ & 0.035 \\
\hline Age, per 10-y increase & $1.15(0.99-1.35)$ & 0.070 & $1.06(0.91-1.23)$ & 0.434 \\
\hline Sex male $V S$ female & $0.79(0.52-1.19)$ & 0.263 & $0.96(0.65-1.41)$ & 0.827 \\
\hline FLT3-ITD, presented $V S$ others & $1.93(1.21-3.07)$ & 0.006 & $1.74(1.12-2.72)$ & 0.014 \\
\hline NPM1, mutated $V S$ wild type & $0.55(0.34-0.87)$ & 0.010 & $0.57(0.37-0.88)$ & 0.012 \\
\hline CEBPA, single mutated $V S$ wild type & $0.79(0.32-1.95)$ & 0.607 & $0.92(0.37-2.25)$ & 0.850 \\
\hline CEBPA, double mutated $V S$ wild type & $0.49(0.21-1.11)$ & 0.088 & $0.51(0.24-1.07)$ & 0.075 \\
\hline
\end{tabular}

Abbreviations: HR, hazards ratio; $\mathrm{CI}$, confidence interval.

\section{Prognostic value of $A T P 1 B 1$ expression}

After dividing the $157 \mathrm{CN}-\mathrm{AML}$ patients into two groups based on the median ATP1B1 expression level, $A T P 1 B 1^{\text {high }}$ expressers showed significantly shorter overall survival (OS) $(P=0.0068$, Figure 3A) and eventfree survival (EFS) $(P=0.0039$, Figure 3B). Further, $A T P 1 B 1^{\text {high }}$ expressers were respectively 1.56 times and 1.55 times as likely to die in the OS $(P=0.042)$ and EFS $(P=0.035)$ multivariable models (See Table 2$)$ after adjustment of several known prognostic factors. We also analyzed the prognostic impact of ATP1B1 expression within ELN genetic categories. In the favorable group ( $n$ =59), no significant differences were detected for OS and EFS (See Figure 3C and 3D). In the intermediate-I group $(n=122)$, however, $A T P 1 B 1^{\text {high }}$ patients were associated with dramatically shorter OS $(P=0.0035$, Figure $3 \mathrm{E})$ and shorter EFS $(P=0.0007$, Figure $3 \mathrm{~F})$. In addition, $A T P 1 B 1^{\text {high }}$ expressers were significantly associated with shorter estimated OS/EFS at 3 years, whether among the entire $157 \mathrm{CN}-\mathrm{AML}$ patient cohort or in the ELN intermediate-I category (See Table S1).

\section{Confirmation that $A T P 1 B 1^{\text {high }}$ is an unfavorable biomarker using an independent cohort}

The prognostic value of $A T P 1 B 1$ expression was further confirmed in an independent cohort of 162 CN-AML patients (GEO no: GSE12417), $(P=0.005$, See Figure S3). Using a cutoff of median expression, $A T P 1 B 1^{\text {high }}$ expressers belonged more to FAB M1 and less to FAB M5 than $A T P 1 B 1^{\text {low }}$ expressers $(P=0.005, P=$ 0.048 , respectively). $A T P 1 B 1^{\text {high }}$ was also associated with higher expression of $E R G, B A A L C, M N 1, W T 1, T C F 4$,

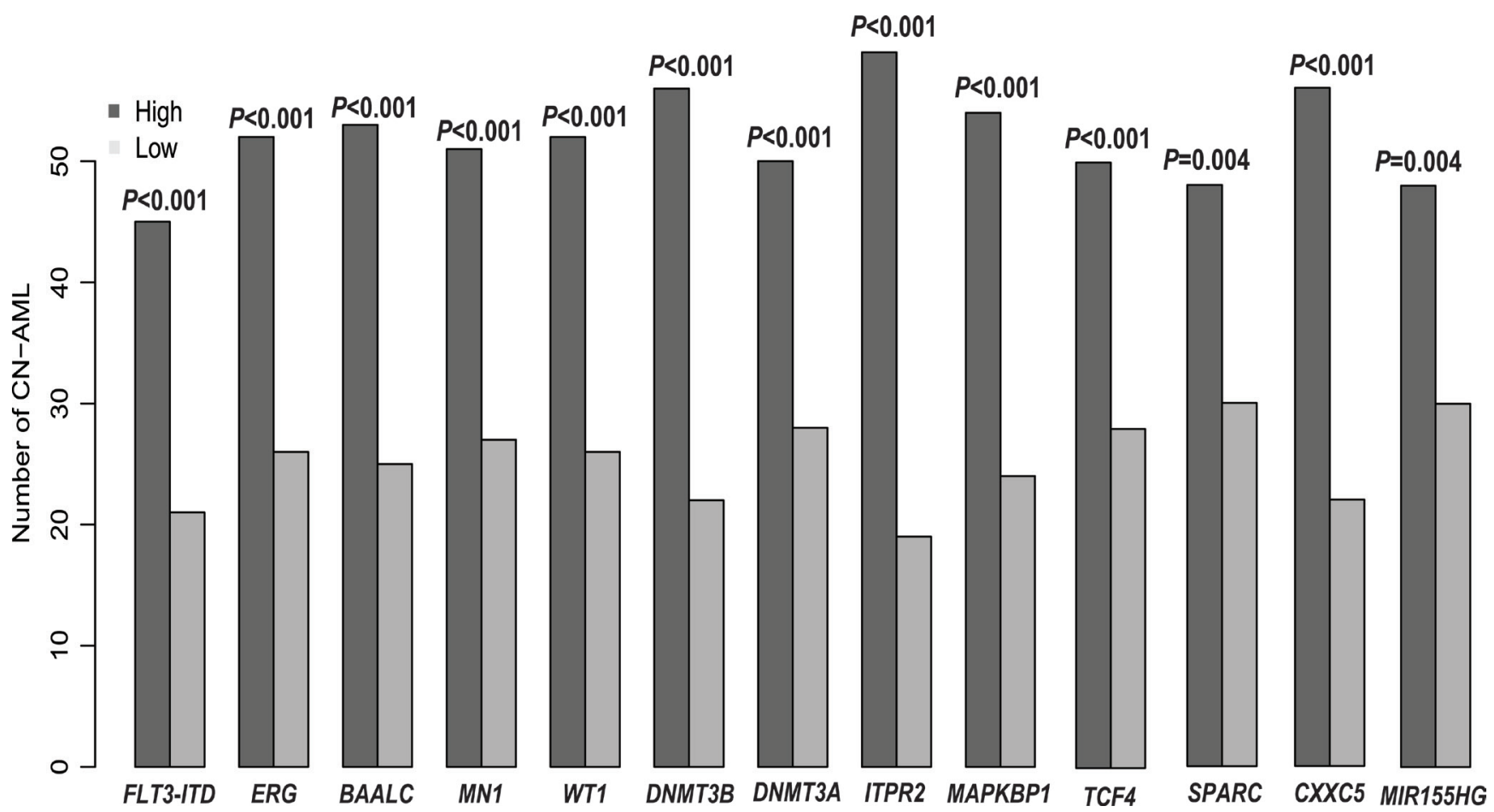

Figure 2: Associations between $A T P 1 B 1$ expression and known prognostic biomarkers. 
SPARC, DNMT3B and ITPR2 (All $P<0.001$, See Table S2 and Figure S2), as was the case with the primary cohort.

\section{Genome-wide gene expression profiles associated with $A T P 1 B 1^{\text {high }}$}

To investigate the mechanisms by which $A T P 1 B 1$ expression affects outcome in CN-AML, we first performed a genome-wide differential analysis after again subdividing the primary cohort of $\mathrm{CN}-\mathrm{AML}$
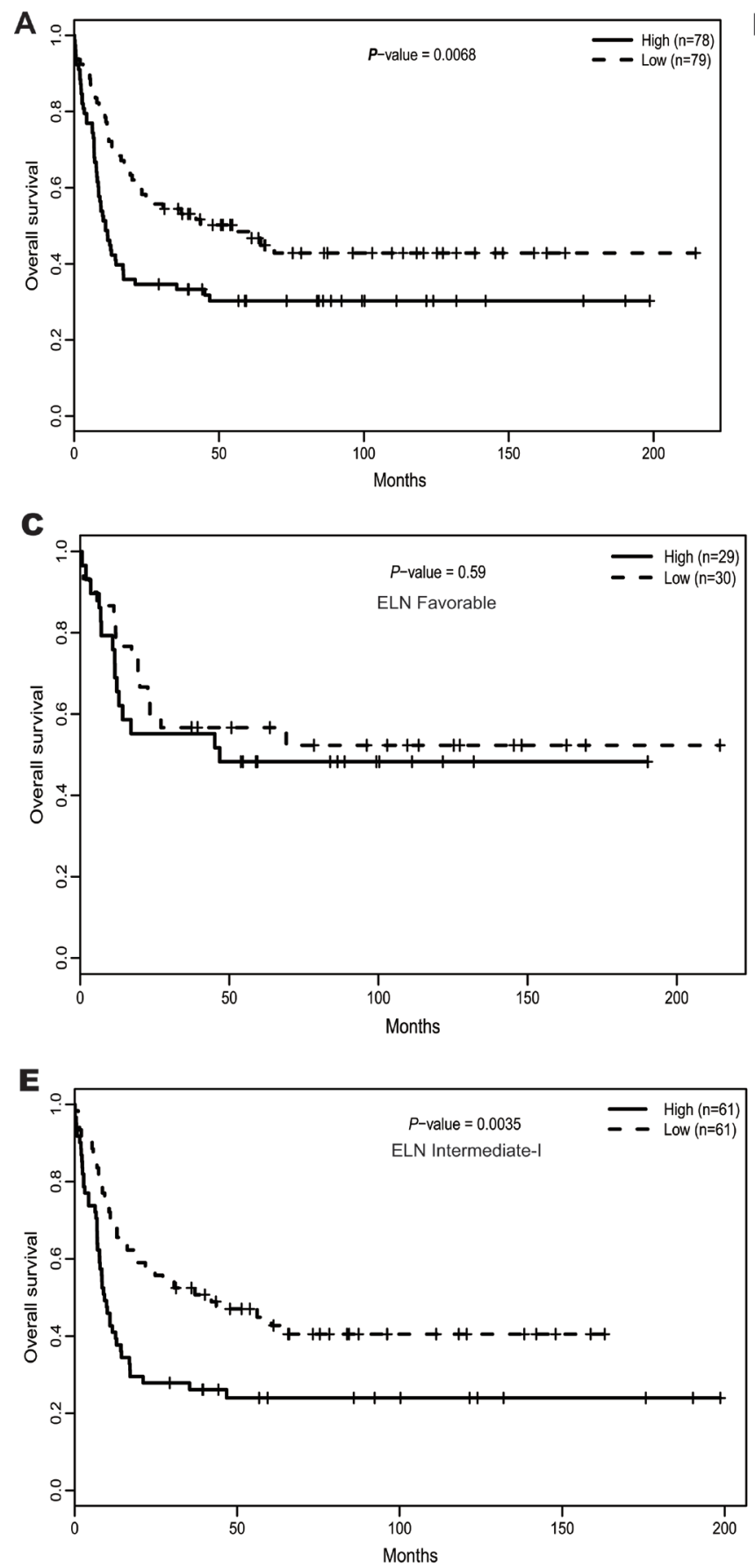

patients based on the median $A T P 1 B 1$ expression. In the $A T P 1 B 1^{\text {high }}$ group, 608 genes were up-regulated and 975 were down-regulated as compared to $A T P 1 B 1^{\text {low }}$ (False Discovery Rate, FDR < 0.05; absolute fold change, FC $\geq 1.5$, See Table S3). Notably, many genes known to be associated with worse outcomes in CN-AML/AML were up-regulated, including WT1 [12], ITPR2 [15], MAPKBP1 [16], BAALC, ERG [11], MN1 [23], SPARC [24], DNMT3B [13], MSI2 [25], GATA2 [26], SOCS2 [27], CXXC5 [18] and MLLT11 [28]. The up-regulated genes also included well-known oncogenes and those previously found to be
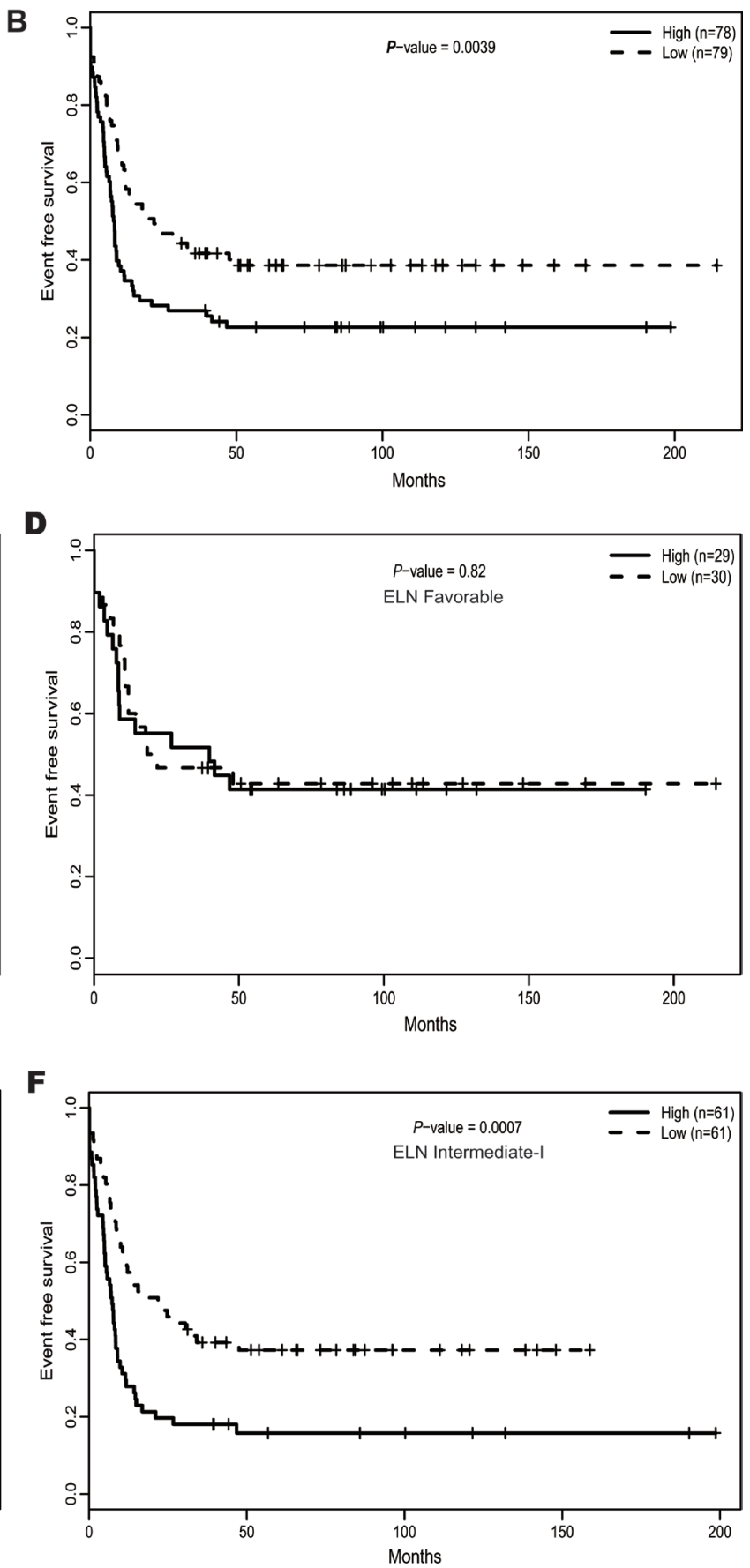

Figure 3: The prognostic value of $\boldsymbol{A T P 1 B 1}$ expression. (A). OS and (B). EFS among the $157 \mathrm{CN}$-AML patients in the primary cohort. (C). OS and (D). EFS in the ELN Favorable category. (E). OS and (F). EFS in the ELN Intermediate-I category. 
involved in leukemogenesis, including MYCN, KIT [29], $C C N D 2$ and $C D K 6$. The encoded proteins include a cyclin kinase, two mitogen-activated protein kinases (MAP4K3, $M A P K 7)$ and a tyrosine kinase (PTK7), which are involved in regulating gene transcription and cell proliferation and differentiation. Other up-regulated genes included CD34, which acts as a marker for hematopoietic progenitor cells, $M P L$, which initiates and maintains RUNX1-ETO AML [30], CD200, whose up-regulation can promote AML progression [31], SOX4, which is a key oncogenic target in C/EBP $\alpha$ mutant AML [32], ETV6, which often cooperates with other oncogenic signals to induce leukemia [33, 34], and $M A P 7$, which is targeted by miR-16 and regulates cell proliferation and the cell cycle in several cancer cell lines [35]. The down-regulated genes included BCL6, THAP2, $I C A M 1$ and $C E B P D$ as well as those encoding members of the toll-like receptor family (TLR4 and TLR8), which can function in pathogen recognition and activation of innate immunity, and $C D 14$ and $C D 86$, which can induce T-cell activation and related immune responses (Figure $4 \mathrm{~A}$ and 4B).

We used pathway data provided by MSgiDB to evaluate cell signaling pathways associated with $A T P 1 B 1^{\text {high }}$. Pathway expression was estimated as the averaged expression of all involved genes. We found that important apoptotic and natural killer signaling pathways were significantly down-regulated, while RNA polymerase and CML pathways were significantly up- regulated (Figure 4E). These findings are consistent with the gene dysregulation summarized above, and suggest why $A T P 1 B 1$ was associated with unfavorable outcomes in CN-AML.

\section{Genome-wide miRNA profiles associated with $A T P 1 B 1$ expression}

Screening for differences in microRNA expression using high-throughput sequencing data from $79 \mathrm{CN}$ AML patients provided by TCGA, we identified 50 differentially expressed microRNAs (FDR $<0.05$ ), including 38 that correlated positively with $A T P 1 B 1$ expression and 12 that correlated negatively (See Table S4). Those positively correlated microRNAs included $m i R-146 b, m i R-125 b, m i R-100$ and $m i R-155(P=0.02)$. MiR-146b binds to the 3'UTR of SMAD4, an important member of TGF- $\beta$ signaling pathway [36]. MiR-155 was previously confirmed to be an independent biomarker of a poorer prognosis in CN-AML [17]. Overexpression of $m i R-125 b$ was shown to independently induce leukemia in a mouse model [37]. And $m i R-100$ blocks the terminal differentiation of myeloid cell by targeting RBSP3 [38]. The most negatively correlated microRNA was $m i R-582$, which reportedly inhibits bladder cancer progression [39]. Other negatively correlated microRNAs included miR-107 and $m i R-223$. $m i R-107$ targets $C E B P A$, which binds to the promoter of $m i R-223$, ultimately inhibiting differentiation
A

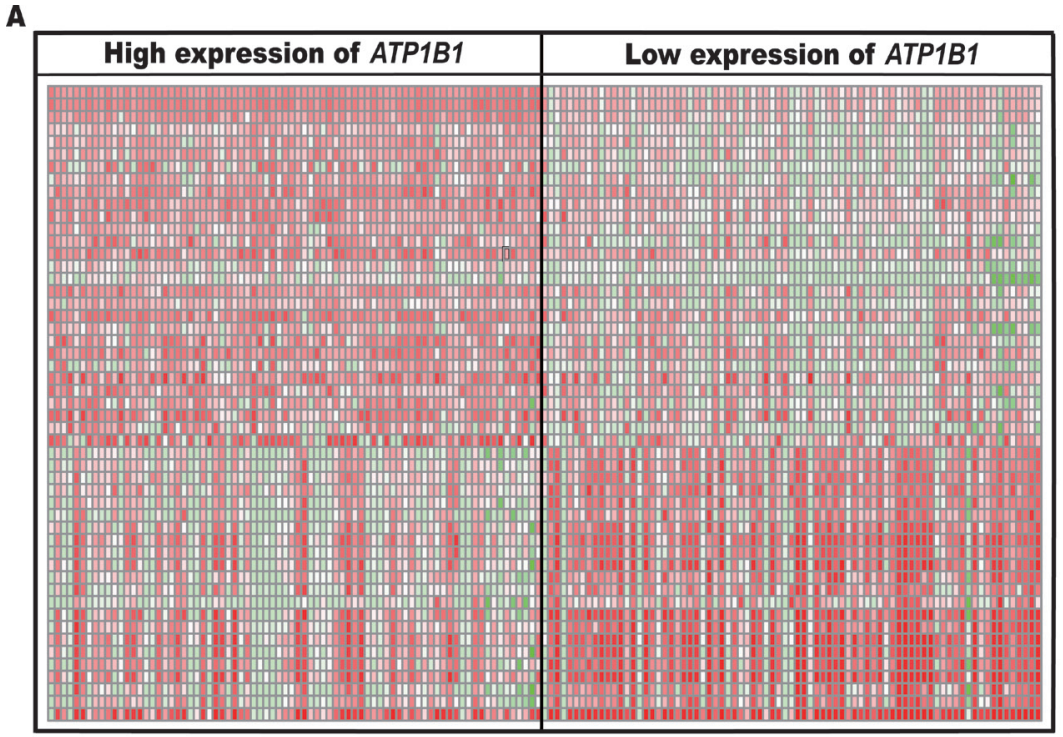

C

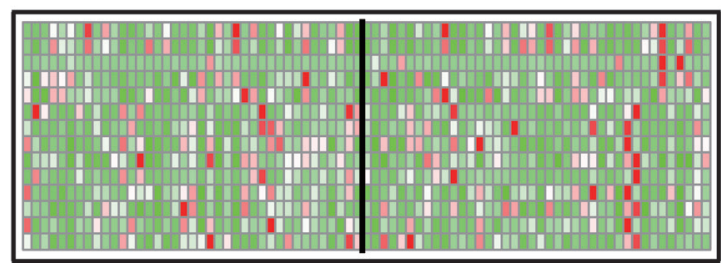

D

\begin{tabular}{|c|c|c|}
\hline microRNA & $\begin{array}{c}\text { Pearson } \\
\text { Coefficient }\end{array}$ & $P$-value \\
\hline miR-146b & 0.61 & $1.90 \mathrm{E}-09$ \\
\hline miR-125b & 0.55 & $2.07 \mathrm{E}-07$ \\
\hline miR-100 & 0.48 & $6.15 \mathrm{E}-06$ \\
\hline miR-155 & 0.26 & 0.02 \\
\hline miR-582 & -0.45 & $2.56 \mathrm{E}-05$ \\
\hline miR-223 & -0.38 & 0.0004 \\
\hline miR-107 & -0.29 & 0.01 \\
\hline miR-193a & -0.24 & 0.036 \\
\hline
\end{tabular}

B

\begin{tabular}{|c|c|c|c|c|c|}
\hline Gene & P-Value & $\begin{array}{c}\text { Log }_{2} \text { FC, } \\
\text { High/Low }\end{array}$ & Gene & P-Value & $\begin{array}{c}\text { Log }{ }_{2} \text { FC, } \\
\text { High/Low }\end{array}$ \\
\hline \multicolumn{2}{|c|}{ Up-Regulated in ATP1B1 $1^{\text {high }}$} & PTK7 & $9.79 E-07$ & 0.86 \\
\hline ATP1B1 & $3.90 E-25$ & 1.69 & MAP7 & $3.39 E-06$ & 0.93 \\
\hline CXXC5 & $2.16 E-08$ & 0.96 & ETV6 & $2.96 E-06$ & 0.98 \\
\hline ITPR2 & $4.35 E-08$ & 0.82 & CCND2 & 0.0001 & 0.69 \\
\hline MSI2 & $8.20 E-08$ & 1.27 & MPL & 0.0004 & 0.81 \\
\hline MLLT11 & $1.04 E-07$ & 0.99 & CD34 & 0.0003 & 1.18 \\
\hline GATA2 & $3.79 E-07$ & 1.15 & CD200 & 0.001 & 0.79 \\
\hline KIT & $7.20 E-06$ & 1.3 & SOCS2 & 0.001 & 1 \\
\hline ERG & $7.48 E-07$ & 1.11 & Down-Regulated in ATP1B1 \\
\hline WT1 & $4.00 \mathrm{E}-06$ & 1.14 & BCL6 & $2.95 \mathrm{E}-08$ & -1.36 \\
\hline DNMT3B & $4.21 \mathrm{E}-06$ & 0.73 & THAP2 & $1.54 \mathrm{E}-05$ & -0.76 \\
\hline SPARC & 0.039 & 0.71 & CEBPD & 0.0001 & -0.92 \\
\hline BAALC & 0.001 & 0.93 & ICAM1 & 0.003 & -0.86 \\
\hline SOCS5 & $1.26 \mathrm{E}-08$ & 0.61 & CD14 & $1.06 \mathrm{E}-05$ & -2.16 \\
\hline MYCN & $3.04 \mathrm{E}-08$ & 2.01 & CD86 & $4.32 \mathrm{E}-05$ & -0.93 \\
\hline CDK6 & $6.90 \mathrm{E}-07$ & 1.04 & TLR8 & $1.004 \mathrm{E}-05$ & -1.55 \\
\hline MAP4K3 & $8.26 \mathrm{E}-07$ & 0.59 & TLR4 & $3.007 \mathrm{E}-05$ & -1.18 \\
\hline
\end{tabular}

E

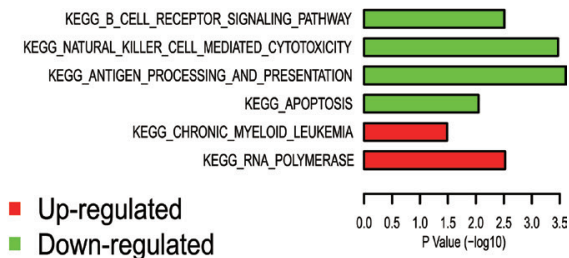

Figure 4: Genes/microRNAs/cell signaling pathways associated with high ATP1B1 expression. (A). Gene expression heat map. (B). List of genes. (C). MicroRNA expression heat map. (D). List of microRNAs. (E). Pathways. 
of granulocytic cells [40]. MiR-193a targets c-KIT and acts as a tumor suppressor in AML (See Figure 4C and 4D) [29].

\section{Genome-wide methylation profiles associated with ATP1B1 expression}

DNA methylation is an important epigenetic mechanism that regulates gene expression, and some methylation loci have been used to predict clinical outcomes in CN-AML [3]. Considering that expression of both $D N M T 3 A$ and $D N M T 3 B$ correlated positively with $A T P 1 B 1$ expression, we carried out a genomewide differential analysis to identify differences in the methylation patterns between $A T P 1 B 1^{\text {high }}$ and $A T P 1 B 1^{\text {low }}$ expressers based on a TCGA AML cohort of 74 CN-AML patients. Surprisingly, comparison of the methylation levels at several different regions (TSS200, TSS1500, Promoter, Body, 3'UTR and 5'UTR, See Figure S4) revealed no significant differences in methylation associated with $A T P 1 B 1$ expression status.

\section{DISCUSSION}

$A T P 1 B 1$ encodes an integral membrane ion pump responsible for maintenance of the $\mathrm{Na}^{+}$and $\mathrm{K}^{+}$ electrochemical gradients across the plasma membrane, and contributes to the establishment of epithelial cell polarity [41] and cell adherence. In an earlier study we showed that strong expression of ITPR2, which encodes a key membrane $\mathrm{Ca}^{2+}$ transporter, is predictive of an unfavorable outcome in CN-AML [15]. The present study demonstrates that overexpression of ATP1B1 may also predict a poor prognosis in CN-AML patients. Together, these studies suggest that metal ion (e.g., $\mathrm{Ca}^{2+}, \mathrm{K}^{+}, \mathrm{Na}^{+}$) transport status has an important impact on outcome in CN-AML.

Our first main finding is that $A T P 1 B 1$ is more strongly expressed in CN-AML than normal BM (Figure $1 \mathrm{~A}$ and $1 \mathrm{~B}$ ), which suggests $A T P 1 B 1$ plays an active role during the pathogenesis of leukemia. The higher ATP1B1 expression was easily detected using qPCR, which is readily applicable for clinical use. In addition, patients with higher $A T P 1 B 1$ expression were classified mainly into the M1 and M2 FAB subgroups, with fewer in the M5 subgroup, suggesting that $A T P 1 B I^{\text {high }}$ expressers carry more immature cells, which likely indicates greater malignancy. $A T P 1 B 1^{\text {high }}$ is significantly associated with FLT3-ITD and shows higher expression in ELN Intermediate-I than in the Favorable category, which are consistent with ATP1BI's prognostic role. However, $A T P 1 B 1$ shows only a trend toward lower expression in CN-AML patients with NPMI mutation, as well as a slight trend toward higher expression in patients with single or double CEBPA mutation, which is not consistent with the known prognostic role of $C E B P A$ mutations. Perhaps there were too few samples with $C E B P A$ mutations (5 with single and 16 with double mutations), and the discrepancy reflects an aberrant result that does not reflect the true efficacy of $C E B P A$ mutation as prognostic indicator.

We also demonstrated that high $A T P 1 B 1$ expression was an unfavorable prognostic biomarker for CN-AML patients, based on clinical and molecular characteristics prior to treatment and OS/EFS across the entire cohort or within ELN categories. These results indicate that ATP1B1 expression could be used for risk stratification, not only with respect to the entire CN-AML patient population, but also within ELN intermediated-I categories, which could facilitate design of more suitable therapies and has important clinical significance. The prognostic value of ATP1B1 was confirmed in another cohort of $162 \mathrm{CN}$ AML patients. Moreover, to avoid possible distortion of the microarray data, high-throughput sequencing data from TCGA was used as a second independent validating dataset, which included $41 \mathrm{CN}-\mathrm{AML}$ patients treated with uniform chemotherapy $(P=0.039$, See Figure S5). All of these results show that overexpression of ATP1B1 is predictive of an adverse outcomes in CN-AML. Because there are no recurrent chromosomal alterations, CN-AML shows a degree of genetic uniformity, which facilitates identification of new biomarkers but limits the scope of their application. We therefore evaluated the prognostic value of ATP1B1 in a cohort of 344 AML samples containing a variety of karyotypes. Notably, overexpression of $A T P 1 B 1$ was associated with a shorter OS and EFS $(P=0.027$ and $P=0.0169$, respectively. See Figure S6), indicating that overexpression of $A T P 1 B 1$ may be an unfavorable biomarker in both CN-AML and AML.

To investigate the potential mechanisms by which $A T P 1 B 1$ expression affects patient outcome, we carried out a multi-omics analysis. The first gene/microRNA expression profiles and methylation loci associated with ATP1B1 expression were determined, including related cell signaling pathways. Many known oncogenes and unfavorable CN-AML biomarkers were found to be upregulated, while various tumor suppressors and immune factors were down-regulated. In addition, important apoptotic and natural killer signaling pathways were all significantly down-regulated, while RNA polymerase and CML pathways were significantly up-regulated. These aberrant changes to the transcriptome likely contribute to the unfavorable outcomes for CN-AML.

MicroRNA-involved regulation and methylation are important epigenetic mechanisms, which play essential roles in many biologic processes, including tumorigenesis. In this study, several microRNAs known to be involved in tumorigenesis were found to be associated with $A T P 1 B 1$ expression, and may represent potentially useful therapeutic targets. No methylation patterns were associated with ATP1B1 expression. Perhaps, demethylation agents would be of no use for patients 
strongly expressing ATP1B1.

In conclusion, our work demonstrates that overexpression of $A T P 1 B 1$ may be a useful unfavorable biomarker for evaluating CN-AML outcomes. Because of its higher expression in CN-AML patients than healthy individuals, ATP1B1 may be easily detected using qPCR in clinical applications. Furthermore, our genome-wide analysis of aberrant gene/microRNA expression and cell signaling may lead to a better understanding of potential leukemogenic mechanisms, thereby aiding development of new therapeutic strategies for the treatment of CN-AML.

\section{MATERIALS AND METHODS}

\section{Patient samples}

This research was approved by the institutional review boards at Weill Cornell Medical College and Erasmus University Medical Center, and all patients provided written informed consent in accordance with the Declaration of Helsinki [47]. The study participants were 157 primarily untreated CN-AML patients (median age: 50 years, range: $16-77$ years). Among them, 130 $(83 \%)$ were aged $<60$ years (younger patients) and 27 $(17 \%)$ were $\geq 60$ years (older patients). Patients were uniformly treated according to the study protocols of the Dutch-Belgian Hematology-Oncology Cooperative Group (HOVON, http://www.hovon.nl). BM aspirates and PB were collected at the time of diagnosis at the Erasmus University Medical Center (Rotterdam) between 1990 and 2008 [45]. The samples all contained 80\%-100\% blast cells after thawing [46]. To make a diagnosis of a normal karyotype, more than 20 metaphases from BM were examined using conventional cytogenetics. NPM1, $C E B P A, I D H 1$ and IDH2 mutations; FLT3-internaltandem duplications (FLT3-ITD); and N-RAS, K-RAS and FLT3-tyrosine kinase domain mutations (FLT3-TKD [D835]) were all assessed. An independent validating cohort of $162 \mathrm{CN}-\mathrm{AML}$ patients all received uniform treatment (intensive double induction and consolidation chemotherapy) based on the multicenter AMLCG-1999 trial of the German AML Cooperative Group between 1999 and 2003 [48]. The AMLCG-1999 clinical trials were approved by the local institutional review boards, and all patients provided written informed consent in accordance with the Declaration of Helsinki.

\section{Microarray studies}

All the microarray data used in our study were derived from the Gene Expression Omnibus (GEO) and were available for public downloading. Expression data for the $157 \mathrm{CN}$-AML patients in the primary cohort were detected using an Affymetrix HG-U133Plus 2.0 array
[45], while the validating cohort of $162 \mathrm{CN}-\mathrm{AML}$ patients was evaluated using an Affymetrix HG-U133A array [49]. High-throughput sequencing data from The Cancer Genome Atlas (TCGA) were also used [50], including mRNA, microRNA and methylation data.

\section{Statistical analysis}

Samples were divided into two groups $\left(A T P 1 B 1^{\text {high }}\right.$, $n=78 ; A T P 1 B 1^{\text {low }}, n=79$ ) based on the median ATP $1 B 1$ expression level. In addition, high and low classifications of ERG, BAALC,WT1, LEF1, MN1, EVI1, DNMT3B, TCF4, ITPR2, MAPKBP1 and MIR155HG were determined according to the median expression of the corresponding genes. When comparing the $A T P 1 B 1^{\text {high }}$ and $A T P 1 B 1^{\text {low }}$ patient groups, Fisher's exact test and the Wilcoxon rank-sum test were used to compare categorical and continuous variables, respectively. Kaplan-Meier and log-rank test were used for survival analysis. Multivariable Cox proportional hazards models were used to study the time-to-event factors associated with survival endpoints. Student's $t$-test was used to identify ATP1B1-associated genes, pathways and methylation sites. Pearson correlation test was performed to detect correlated expression between $A T P 1 B 1$ and microRNA sequencing profiles. All analyses were performed using R 3.1.1.

\section{ACKNOWLEDGMENTS}

The work was supported by grants from the National Natural Science Foundation of China (61501519, 81500118 and 61372047 61372047, 61501519 and 81500118), the National High-tech R\&D Program of China (2013BAI03B04), Chinese PLA General Hospital Nursery Foundation (14KMM38).

\section{CONFLICTS OF INTEREST}

The authors report no potential conflict of interest.

\section{REFERENCES}

1. Mrozek K, Heerema NA, Bloomfield CD. Cytogenetics in acute leukemia. Blood reviews. 2004; 18(2):115-136.

2. Dohner, H., E. H. Estey, S. Amadori, F. R. Appelbaum, T. Buchner, A. K. Burnett, H. Dombret, P. Fenaux, D. Grimwade, R. A. Larson, F. Lo-Coco, T. Naoe, D. Niederwieser, et al. Diagnosis and management of acute myeloid leukemia in adults: recommendations from an international expert panel, on behalf of the European LeukemiaNet. Blood. 2010; 115(3):453-474.

3. Deneberg, S., P. Guardiola, A. Lennartsson, Y. Qu, V. Gaidzik, O. Blanchet, M. Karimi, S. Bengtzen, H. Nahi, B. Uggla, U. Tidefelt, M. Hoglund, C. Paul, et al. Prognostic DNA methylation patterns in cytogenetically normal acute 
myeloid leukemia are predefined by stem cell chromatin marks. Blood. 2011; 118(20):5573-5582.

4. Dohner, K., R. F. Schlenk, M. Habdank, C. Scholl, F. G. Rucker, A. Corbacioglu, L. Bullinger, S. Frohling and H. Dohner. Mutant nucleophosmin (NPM1) predicts favorable prognosis in younger adults with acute myeloid leukemia and normal cytogenetics: interaction with other gene mutations. Blood. 2005; 106(12):3740-3746.

5. Marcucci, G., K. Maharry, M. D. Radmacher, K. Mrozek, T. Vukosavljevic, P. Paschka, S. P. Whitman, C. Langer, C. D. Baldus, C. G. Liu, A. S. Ruppert, B. L. Powell, A. J. Carroll, et al. Prognostic significance of, and gene and microRNA expression signatures associated with, CEBPA mutations in cytogenetically normal acute myeloid leukemia with high-risk molecular features: a Cancer and Leukemia Group B Study. Journal of clinical oncology. 2008; 26(31):5078-5087.

6. Whitman, S. P., K. Maharry, M. D. Radmacher, H. Becker, K. Mrozek, D. Margeson, K. B. Holland, Y. Z. Wu, S. Schwind, K. H. Metzeler, J. Wen, M. R. Baer, B. L. Powell, et al. FLT3 internal tandem duplication associates with adverse outcome and gene- and microRNA-expression signatures in patients 60 years of age or older with primary cytogenetically normal acute myeloid leukemia: a Cancer and Leukemia Group B study. Blood. 2010; 116(18):36223626.

7. Gaidzik, V. I., R. F. Schlenk, S. Moschny, A. Becker, L. Bullinger, A. Corbacioglu, J. Krauter, B. Schlegelberger, A. Ganser, H. Dohner, K. Dohner and A. M. L. S. G. German-Austrian. Prognostic impact of WT1 mutations in cytogenetically normal acute myeloid leukemia: a study of the German-Austrian AML Study Group. Blood. 2009; 113(19):4505-4511.

8. Gaidzik, V. I., R. F. Schlenk, P. Paschka, A. Stolzle, D. Spath, A. Kuendgen, M. von Lilienfeld-Toal, W. Brugger, H. G. Derigs, S. Kremers, R. Greil, A. Raghavachar, M. Ringhoffer, et al. Clinical impact of DNMT3A mutations in younger adult patients with acute myeloid leukemia: results of the AML Study Group (AMLSG). Blood. 2013; 121(23):4769-4777.

9. Metzeler, K. H., K. Maharry, M. D. Radmacher, K. Mrozek, D. Margeson, H. Becker, J. Curfman, K. B. Holland, S. Schwind, S. P. Whitman, Y. Z. Wu, W. Blum, B. L. Powell, et al. TET2 mutations improve the new European LeukemiaNet risk classification of acute myeloid leukemia: a Cancer and Leukemia Group B study. Journal of clinical oncology. 2011; 29(10):1373-1381.

10. Garzon, R., S. Volinia, D. Papaioannou, D. Nicolet, J. Kohlschmidt, P. S. Yan, K. Mrozek, D. Bucci, A. J. Carroll, M. R. Baer, M. Wetzler, T. H. Carter, B. L. Powell, et al. Expression and prognostic impact of lncRNAs in acute myeloid leukemia. Proceedings of the National Academy of Sciences of the United States of America. 2014; 111(52):18679-18684.

11. Schwind, S., G. Marcucci, K. Maharry, M. D. Radmacher,
K. Mrozek, K. B. Holland, D. Margeson, H. Becker, S. P. Whitman, Y. Z. Wu, K. H. Metzeler, B. L. Powell, J. E. Kolitz, et al. BAALC and ERG expression levels are associated with outcome and distinct gene and microRNA expression profiles in older patients with de novo cytogenetically normal acute myeloid leukemia: a Cancer and Leukemia Group B study. Blood. 2010; 116(25):56605669.

12. Lyu, X., Y. Xin, R. Mi, J. Ding, X. Wang, J. Hu, R. Fan, X. Wei, Y. Song and R. Y. Zhao. Overexpression of Wilms tumor 1 gene as a negative prognostic indicator in acute myeloid leukemia. PloS one. 2014; 9(3): e92470.

13. C Niederwieser JK, S Volinia, S P Whitman, K H Metzeler, A-K Eisfeld, K Maharry, P Yan, D Frankhouser, H Becker, S Schwind, A J Carroll, D Nicolet, J H Mendler, et al. Prognostic and biologic significance of DNMT3B expression in older patients with cytogenetically normal primary acutemyeloid leukemia. Leukemia. 2015; 29(3):567-75.

14. In 't Hout FE, van der Reijden BA, Monteferrario D, Jansen $\mathrm{JH}$, Huls G. High expression of transcription factor 4 (TCF4) is an independent adverse prognostic factor in acute myeloid leukemia that could guide treatment decisions. Haematologica. 2014; 99(12):e257-9.

15. Shi JL, Fu L, Wang WD. High expression of inositol 1,4,5-trisphosphate receptor, type 2 (ITPR2) as a novel biomarker for worse prognosis in cytogenetically normal acute myeloid leukemia. Oncotarget. 2015; 6(7):5299-5309. doi: 10.18632/oncotarget.3024.

16. Fu, L., J. Shi, K. Hu, J. Wang, W. Wang and X. Ke. Mitogen-activated protein kinase binding protein 1 (MAPKBP1) is an unfavorable prognostic biomarker in cytogenetically normal acute myeloid leukemia. Oncotarget. 2015; 6(10):8144-54. doi: 10.18632/oncotarget.3519.

17. Marcucci, G., K. S. Maharry, K. H. Metzeler, S. Volinia, Y. Z. Wu, K. Mrozek, D. Nicolet, J. Kohlschmidt, S. P. Whitman, J. H. Mendler, S. Schwind, H. Becker, A. K. Eisfeld, et al. Clinical role of microRNAs in cytogenetically normal acute myeloid leukemia: miR-155 upregulation independently identifies high-risk patients. Journal of clinical oncology. 2013; 31(17):2086-2093.

18. Kuhnl, A., P. J. Valk, M. A. Sanders, A. Ivey, R. K. Hills, K. I. Mills, R. E. Gale, M. F. Kaiser, R. Dillon, M. Joannides, A. Gilkes, T. Haferlach, S. Schnittger, et al. Down-regulation of the Wnt inhibitor CXXC5 predicts a better prognosis in acute myeloid leukemia. Blood. 2015; 125(19):2985-94.

19. Shi Jinlong, Fu Lin, Li Yonghui, Yu Li, Weidong W. Identification of let-7a-2-3p or/and miR-188-5p as Prognostic Biomarkers in Cytogenetically Normal Acute Myeloid Leukemia. PloS one. 2015; 10(2):e0118099.

20. Xu ZW, Wang FM, Gao MJ, Chen XY, Hu WL, Xu RC. Targeting the $\mathrm{Na}(+) / \mathrm{K}(+)$-ATPase alphal subunit of hepatoma HepG2 cell line to induce apoptosis and cell cycle arresting. Biological \& pharmaceutical bulletin. 2010; 
33(5):743-751.

21. Yin, W., W. Cheng, W. Shen, L. Shu, J. Zhao, J. Zhang and Z. C. Hua. Impairment of $\mathrm{Na}(+), \mathrm{K}(+)$-ATPase in CD95(APO-1)-induced human T-cell leukemia cell apoptosis mediated by glutathione depletion and generation of hydrogen peroxide. Leukemia. 2007; 21(8):1669-1678.

22. Yin, W., X. Li, S. Feng, W. Cheng, B. Tang, Y. L. Shi and Z. C. Hua. Plasma membrane depolarization and $\mathrm{Na}, \mathrm{K}-$ ATPase impairment induced by mitochondrial toxins augment leukemia cell apoptosis via a novel mitochondrial amplification mechanism. Biochemical pharmacology. 2009; 78(2):191-202.

23. Langer, C., G. Marcucci, K. B. Holland, M. D. Radmacher, K. Maharry, P. Paschka, S. P. Whitman, K. Mrozek, C. D. Baldus, R. Vij, B. L. Powell, A. J. Carroll, J. E. Kolitz, et al. Prognostic importance of MN1 transcript levels, and biologic insights from MN1-associated gene and microRNA expression signatures in cytogenetically normal acute myeloid leukemia: a cancer and leukemia group B study. Journal of clinical oncology. 2009; 27(19):3198-3204.

24. Alachkar, H., R. Santhanam, K. Maharry, K. H. Metzeler, X. Huang, J. Kohlschmidt, J. H. Mendler, J. M. Benito, C. Hickey, P. Neviani, A. M. Dorrance, M. Anghelina, J. Khalife, et al. SPARC promotes leukemic cell growth and predicts acute myeloid leukemia outcome. The Journal of clinical investigation. 2014(4); 124:1512-1524.

25. Byers RJ, Currie T, Tholouli E, Rodig SJ, Kutok JL. MSI2 protein expression predicts unfavorable outcome in acute myeloid leukemia. Blood. 2011; 118(10):2857-2867.

26. Vicente, C., I. Vazquez, A. Conchillo, M. A. GarciaSanchez, N. Marcotegui, O. Fuster, M. Gonzalez, M. J. Calasanz, I. Lahortiga and M. D. Odero. Overexpression of GATA2 predicts an adverse prognosis for patients with acute myeloid leukemia and it is associated with distinct molecular abnormalities. Leukemia. 2012; 26(3):550-554.

27. Laszlo, G. S., R. E. Ries, C. J. Gudgeon, K. H. Harrington, T. A. Alonzo, R. B. Gerbing, S. C. Raimondi, B. A. Hirsch, A. S. Gamis, S. Meshinchi and R. B. Walter. High expression of suppressor of cytokine signaling-2 predicts poor outcome in pediatric acute myeloid leukemia: a report from the Children's Oncology Group. Leukemia \& lymphoma. 2014; 55(12):2817-2821.

28. Xiong, Y., Z. Li, M. Ji, A. C. Tan, J. Bemis, J. V. Tse, G. Huang, J. Park, C. Ji, J. Chen, L. T. Bemis, K. D. Bunting and W. Tse. MIR29B regulates expression of MLLT11 (AF1Q), an MLL fusion partner, and low MIR29B expression associates with adverse cytogenetics and poor overall survival in AML. British journal of haematology. 2011; 153(6):753-757.

29. Gao, X. N., J. Lin, Y. H. Li, L. Gao, X. R. Wang, W. Wang, H. Y. Kang, G. T. Yan, L. L. Wang and L. Yu. MicroRNA-193a represses c-kit expression and functions as a methylation-silenced tumor suppressor in acute myeloid leukemia. Oncogene. 2011; 30(31):3416-3428.

30. Pulikkan, J. A., D. Madera, L. Xue, P. Bradley, S. F.
Landrette, Y. H. Kuo, S. Abbas, L. J. Zhu, P. Valk and L. H. Castilla. Thrombopoietin/MPL participates in initiating and maintaining RUNX1-ETO acute myeloid leukemia via PI3K/AKT signaling. Blood. 2012; 120(4):868-879.

31. Memarian, A., M. Nourizadeh, F. Masoumi, M. Tabrizi, A. H. Emami, K. Alimoghaddam, J. Hadjati, M. Mirahmadian and M. Jeddi-Tehrani. Upregulation of CD200 is associated with Foxp3+ regulatory $\mathrm{T}$ cell expansion and disease progression in acute myeloid leukemia. Tumour biology : the journal of the International Society for Oncodevelopmental Biology and Medicine. 2013; 34(1):531-542.

32. Zhang, H., M. Alberich-Jorda, G. Amabile, H. Yang, P. B. Staber, A. Di Ruscio, R. S. Welner, A. Ebralidze, J. Zhang, E. Levantini, V. Lefebvre, P. J. Valk, R. Delwel, et al. Sox4 is a key oncogenic target in C/EBPalpha mutant acute myeloid leukemia. Cancer cell. 2013; 24(5):575-588.

33. Perna F, Abdel-Wahab O, Levine RL, Jhanwar SC, Imada K, Nimer SD. ETV6-ABL1-positive "chronic myeloid leukemia": clinical and molecular response to tyrosine kinase inhibition. Haematologica. 2011; 96(2):342-343.

34. Nofrini, V., L. Berchicci, R. La Starza, P. Gorello, D. Di Giacomo, F. Arcioni, V. Pierini, B. Crescenzi, S. Romoli, C. Matteucci and C. Mecucci. MN1-ETV6 fusion gene arising from MDS with 5q. Leukemia research. 2011; 35(7):e123-126.

35. Yan, X., H. Liang, T. Deng, K. Zhu, S. Zhang, N. Wang, X. Jiang, X. Wang, R. Liu, K. Zen, C. Y. Zhang, Y. Ba and $X$. Chen. The identification of novel targets of miR-16 and characterization of their biological functions in cancer cells. Molecular cancer. 2013; 12:92.

36. Geraldo MV, Yamashita AS, Kimura ET. MicroRNA miR-146b-5p regulates signal transduction of TGF-beta by repressing SMAD4 in thyroid cancer. Oncogene. 2012; 31(15):1910-1922.

37. Bousquet M, Harris MH, Zhou B, Lodish HF. MicroRNA miR-125b causes leukemia. Proceedings of the National Academy of Sciences of the United States of America. 2010; 107(50):21558-21563.

38. Zheng, Y. S., H. Zhang, X. J. Zhang, D. D. Feng, X. Q. Luo, C. W. Zeng, K. Y. Lin, H. Zhou, L. H. Qu, P. Zhang and Y. Q. Chen. MiR-100 regulates cell differentiation and survival by targeting RBSP3, a phosphatase-like tumor suppressor in acute myeloid leukemia. Oncogene. 2012; 31(1):80-92.

39. Uchino, K., F. Takeshita, R. U. Takahashi, N. Kosaka, K. Fujiwara, H. Naruoka, S. Sonoke, J. Yano, H. Sasaki, S. Nozawa, M. Yoshiike, K. Kitajima, T. Chikaraishi, et al. Therapeutic effects of microRNA-582-5p and $-3 p$ on the inhibition of bladder cancer progression. Molecular therapy : the journal of the American Society of Gene Therapy. 2013; 21(3):610-619.

40. Fazi, F., A. Rosa, A. Fatica, V. Gelmetti, M. L. De Marchis, C. Nervi and I. Bozzoni. A minicircuitry comprised of microRNA-223 and transcription factors NFI-A and C/ EBPalpha regulates human granulopoiesis. Cell. 2005; 
123(5):819-831.

41. Padilla-Benavides, T., M. L. Roldan, I. Larre, D. FloresBenitez, N. Villegas-Sepulveda, R. G. Contreras, M. Cereijido and L. Shoshani. The polarized distribution of $\mathrm{Na}+, \mathrm{K}+-\mathrm{ATPase}$ : role of the interaction between $\{\mathrm{beta}\}$ subunits. Molecular biology of the cell. 2010; 21(13):22172225.

42. Elton TS, Selemon H, Elton SM, Parinandi NL. Regulation of the MIR155 host gene in physiological and pathological processes. Gene. 2013; 532(1):1-12.

43. Kaiser J. Genes link epigenetics and cancer. Science. 2010(6004); 330:577.

44. Yang X, Han H, De Carvalho DD, Lay FD, Jones PA, Liang G. Gene body methylation can alter gene expression and is a therapeutic target in cancer. Cancer cell. 2014; 26(4):577590.

45. Verhaak, R. G., B. J. Wouters, C. A. Erpelinck, S. Abbas, H. B. Beverloo, S. Lugthart, B. Lowenberg, R. Delwel and P. J. Valk. Prediction of molecular subtypes in acute myeloid leukemia based on gene expression profiling. Haematologica. 2009; 94(1):131-134.

46. Valk, P. J., R. G. Verhaak, M. A. Beijen, C. A. Erpelinck, S. Barjesteh van Waalwijk van Doorn-Khosrovani, J. M. Boer, H. B. Beverloo, M. J. Moorhouse, P. J. van der Spek, B. Lowenberg and R. Delwel. Prognostically useful geneexpression profiles in acute myeloid leukemia. The New England journal of medicine. 2004; 350(16):1617-1628.

47. Figueroa, M. E., S. Lugthart, Y. Li, C. ErpelinckVerschueren, X. Deng, P. J. Christos, E. Schifano, J. Booth, W. van Putten, L. Skrabanek, F. Campagne, M. Mazumdar, J. M. Greally, et al. DNA methylation signatures identify biologically distinct subtypes in acute myeloid leukemia. Cancer cell. 2010; 17(1):13-27.

48. Buchner, T., W. E. Berdel, C. Schoch, T. Haferlach, H. L. Serve, J. Kienast, S. Schnittger, W. Kern, J. Tchinda, A. Reichle, E. Lengfelder, P. Staib, W. D. Ludwig, et al. Double induction containing either two courses or one course of high-dose cytarabine plus mitoxantrone and postremission therapy by either autologous stem-cell transplantation or by prolonged maintenance for acute myeloid leukemia. Journal of clinical oncology. 2006; 24(16):2480-2489.

49. Metzeler, K. H., M. Hummel, C. D. Bloomfield, K. Spiekermann, J. Braess, M. C. Sauerland, A. Heinecke, M. Radmacher, G. Marcucci, S. P. Whitman, K. Maharry, P. Paschka, R. A. Larson, et al. An 86-probe-set geneexpression signature predicts survival in cytogenetically normal acute myeloid leukemia. Blood. 2008; 112(10):4193-4201.

50. The Cancer Genome Atlas Research N. Genomic and epigenomic landscapes of adult de novo acute myeloid leukemia. The New England journal of medicine. 2013; 368(22):2059-2074. 